DOI 10.37882/2223-2982.2021.12.19

\title{
ДИСКУРСИВНЫЕ ПРАКТИКИ НЕМЕЦКОЙ КИНОКРИТИКИ В ВЕЙМАРСКОЙ РЕСПУБЛИКЕ
}

\section{DISCURSIVE PRACTICES OF GERMAN FILM CRITICS IN THE WEIMAR REPUBLIC \\ A. Novikova}

Summary: With the emergence of cinema in the Weimar Republic, we can talk about the separation of the discourse of film criticism, which reflects the diversity of opinions about the art of cinema of the Weimar Republic. The meanings and images enshrined in the language of film criticism are the most important factor in establishing trends in the evolution of film criticism discourse. The analysis of the discourse of film criticism, mediated by the means of language, makes it possible to objectively evaluate discursive practices and identify the features of textual culture in the field of theory and criticism of cinema in the Weimar Republic in development. The article presents the results of a study, as a result of which the features of the discourse of German film criticism of various professional groups were revealed on the example of a key communicative event in the cinema of the Weimar Republic of 19301931 - the film «The Blue Angel».

Keywords: discourse, discursive strategies, discourse analysis, key event, cinematographic discourse of the Weimar Republic, historical discourse studies.

\section{Введение}

И скусство кино является своего рода сейсмографом социокультурных изменений общества, зеркалом его настроения. С появлением кино зарождается и кинокритика. Расцвет немецкого кинематографа в Веймарской республике происходит во время непростой социальной и политической обстановки, что непосредственно оказывает влияние не только на сюжет самих фильмов, но и на язык кинокритиков. Дискурс кинокритики, являясь частью гетерогенного дискурса киноискусства, отражает многообразие мнений об искусстве кино. В современной лингвистике исследуются различные аспекты этого вида дискурса как на материале русского языка [Шкайдерова 2014], так и на материале английского [Ванько 2013, 2021] и немецкого [Эрман 2011] языков.

В настоящей статье представлен ретроспективный взгляд на немецкую кинокритику в Веймарской республике.

Цель статьи заключается в выявлении дискурсивных стратегий и в раскрытии вариативных языковых средств дискурса кинокритики в Веймарской республике с 1930
Новикова Алена Сергеевна

аспирант, Московский Государственный

Лингвистический университет; ассистент, Российский университет дружбы народов (2. Москва), alenuchka.noff90@gmail.com

Аннотация: ( возникновением кино в Веймарской республике можно говорить 0 выделении дискурса кинокритики, который отражает многообразие мнений об искусстве кино Веймарской республики. Смыслы и образы, закреплённые в языке кинокритики, являются важнейшим фактором установления тенденций эволюции дискурса кинокритики. Его анализ, опосредованный средствами языка, позволяет объективно оценить дискурсивные практики и выявить особенности текстовой культуры в области теории и критики кино Веймарской республики в развитии. В статье представлены результаты исследования, выявившего особенности дискурсивных практик немецкой кинокритики на примере ключевого коммуникативного события в киноискусстве Веймарской республики 1930-1931гг. - фильма «Голубой ангел».

Ключевые слова: дискурс, дискурсивные стратегии, дискурсивный анализ, ключевое событие, кинематографический дискурс Веймарской республики, историческая дискурсология.

по 1931 гг. для решения прагматической задачи автора кинорецензии.

Актуальность исследования вытекает из востребованности изучения взаимодействия языка и социума, различных видов дискурса, в том числе, их становление и эволюцию в определенные исторические периоды развития общества, а также из необходимости анализа тенденций развития текстовой культуры и дискурсивных практик в теории и критики кино Веймарской республики.

Материалом исследования послужили рецензии специалистов, ориентированные на широкий круг читателей, опубликованные в общенациональных газетах Веймарской республики с 1930 по 1931 гг., отражавших интересы различных социальных групп. В данной статье не рассматриваются кинорецензии специалистов в профессиональных изданиях [«Film-Kurier», «Kinematograph», «Arbeiterbühne und Film», «LichtbildBühne»]. Были проанализированы 82 номера следующих изданий с размещенными в них рецензиями: газета социал-демократической партии Германии «Vorwärts» (25 номеров); газета правых консервативных анти-респу- 
бликанских сил Германии «Deutsche Allgemeine Zeitung» (25 номеров); журнал радикал-демократических левых сил Германии «Weltbühne» (20 номеров); журнал пролетарских писателей, разделявших идеи коммунистической партии Германии «Linkskurve» (12 номеров).

\section{$\triangle$ искурсивные практики немешкой кинокритики в Веймарской республике}

\section{Дискурс кинокритики}

Мы исходим из того, что анализ дискурса кинокритики Веймарской республики представляет собой сложное явление социального взаимодействия как представителей профессионального сообщества, так и общественности (зрителей и читателей) - рефлексивную письменную коммуникацию в области искусства кино в развитии.

Выбор темы обусловлен развитием нового направления в когнитивно-дискурсивных исследованиях - исторической дискурсологии. Историческая дискурсология исследует тексты прошлых эпох с целью установления тенденций эволюции частных дискурсов, в нашем случае - дискурса кинокритики Веймарской республики. Исследуя тексты различных исторических периодов, «можно сделать некоторые заключения об их дискурсивных особенностях, то есть особенностях использования языка как компонента определенной социальной деятельности людей „в поставленных им целях и в определенном историческом контексте"» [Кочетова, Ильинова, 2017, с. 11].

Л.И. Кочетова и Е.Ю. Ильинова высказали точку зрения о том, что «дискурс создает текст, который оказывается регистрацией самой коммуникативной деятельности, осуществленной, например, в письменной форме» [Кочетова, Ильинова, 2017, с. 11].

Отправной точкой ретроспективного изучения дискурса немецкой кинокритики как социальной деятельности мы считаем следующую идею Е.С. Кубряковой: «...поскольку тип дискурса детерминируется типом той социальной активности человека, в рамках которой он осуществляется, и с целями которой он согласуется, следует сказать, что сами типы подобной активности исторически обусловлены и напрямую связаны с уровнем развития общества и его культурой» [Кубрякова 2004, с. 525-526]. Утверждение Е.С. Кубряковой о том, что «дискурс всегда есть детище своего времени» [Кубрякова, 2004, с. 526], важно при изучении стиля проведения дискурсивной деятельности, в нашем случае - в киноискусстве Веймарской республики, включающей языковые средства реализации прагматической цели автора, выбор которых может зависеть от «состояния общества и тех социальных ролей, которые в этом обществе может играть человек» [Кубрякова, 2004, с. 526]. Мы отмечаем, что социальный контекст в таком случае является значи- мым для изучения дискурса в ретроспективном ракурсе.

В статье мы также опираемся на мнение Ю.С. Степанова о том, что использование языка есть выражение особой ментальности [Степанов 1995, с. 38-39], это не только «язык в действии», но и «язык как определенный компонент социальной деятельности людей». Язык становится, таким образом, непременной составной частью самой деятельности, «носящей отпечаток своего времени» [там же, с. 38].

\section{Веймарское кино}

Первый период расцвета немецкого кино известен как «Веймарское кино»; он пользовался всемирным успехом, особенно в первой половине 1920-х годов. История немецкого кино начинается с основания молодой республики и заканчивается приходом к власти национал-социалистов в 1933 году. Переход от немого кино к звуковому означает смену парадигмы не только с технической, но и с экономической и эстетической точек зрения. Начало немецкого кино связывают с 27 февраля 1920 года, когда состоялась премьера фильма «Кабинет доктора Калигари» Роберта Вине. До этого критики заявляли, что в Германии не было собственной киноиндустрии. С зарождением немецкого экспрессионистского кино в 1920 году и окончательным его концом в 1933 году короткий период высокопродуктивного немецкого кинопроизводства почти полностью совпадает со временем Веймарской республики и поэтому часто называется «Веймарским кино».

\section{Дискурсивные стратегии в немецкой кинорецензии}

В изучении дискурсивных стратегий мы опираемся на исследования О.С. Иссерс [1999] и Т.Б. Троицкой [2008] по типологии дискурсивных стратегий, в частности, на положение Т.Б. Троицкой о том, что «дискурсивная стратегия обладает четкой ориентированной целевой доминантой, развивается субъектом речи в определенных условиях ее порождения и выявляется адресатом в соответствующей совокупности текстов» [Троицкая, 2008, с. 81].

В Веймарской республике с расцветом немецкого кинематографа сформировалась и влиятельная кинокритика, крупнейшими фигурами которой были Рудольф Арнхейм, Бела Балаш, Зигфрид Кракауэр, Лотте Айснер, Франц Кафка, Макс Брод, Ганс Волленберг, рецензии которых проанализированы в настоящей статье.

Мы исходим из того, что авторы кинорецензий, в том числе и выдающиеся вышеупомянутые кинокритики того времени, размещая материалы в том или ином издании, ориентированном на определённую группу читателей, представляли интересы этого издания. Иными словами, принадлежность автора к определенной соци- 
альной группе является отправной точкой дискурсивного ретроспективного анализа, позволяющего раскрыть особенности текстовой культуры кинорецензии на примере ключевого события в немецком кинематографе Веймарской республики - фильме «Голубой ангел». Под ключевым коммуникативным событием в кинематографе мы подразумеваем наиболее обсуждаемое событие в прессе того времени - в главном средстве массовой коммуникации того времени.

Представленные в прессе того времени кинорецензии были разделены нами на следующие типы: Rezension (рецензия); Besprechung (рецензия-обсуждение); Kommentar (комментарий); Übersicht (обзор).

В настоящей статье будут представлены результаты исследования только по типу Rezension (рецензия).

В ходе исследования нами были выделены три основных стратегии на основании той коммуникативной интенции, которую они выполняют в рамках дискурса немецкой кинокритики в Веймарской республике: стратегия информирования, стратегии оценивания, стратегия влияния на адресата.

Стратегия информирования выполняет функцию донесения информации до адресата.

Стратегия оценивания нацелена на профессиональное суждение о фильме. В этой связи мы выделяем стратегию формирования положительной или отрицательной оценки.

При написании кинорецензий критик не только преследует цель донесения информации, но он также заинтересован в том, чтобы эта информация была принята адресатом, т. е. реализует стратегию влияния на читателя. При воздействии на адресата автор кинорецензии прибегает к тактике аргументирования.

Далее в статье будут представлены языковые средства реализации дискурсивных стратегий авторами кинорецензий.

Рамки статьи не позволяют представить результаты анализа всех четырех изданий, мы ограничимся результатами исследования рецензий в газетах «Vorwärts» и «Deutsche Allgemeine Zeitung», представлявших интересы диаметрально противоположных социальных групп и политических сил.

В рецензиях газеты «Vorwärts» стратегия информирования находит отражение в следующих самых частотных лексических единицах (преобладают существительные и субстантивные словосочетания):

1. Сведения о месте показа фильма: in zwei Theatern Freitag, Sonnabend, Sonntag in vier Vorstellungen sowie eine Nachtvorstellung [«Vorwärts» 1930, №17]; Gloria-Palast. Erster Sprechfilm [«Vorwärts» 1930, № 15,17]; der beste Sprech- und Tonfilm der „UFA" [«Vorwärts» 1930 № 198].

2. Сведения о киностудии / съёмочной группе / режиссере/актерах:

ein Tonfilm der Erich Pommer Produktion der Ufa mit Marlen Dietrich, Rosa Valetti, Hans Albers, Wilhelm Diegelmann, Curt Gerron, Eduard v. Winterstein; Regie von Josepf von Sternberg [«Vorwärts» 1930, № 15, 17, № 198; 1931 № 9, 11,15,23]; Drehbuch: Robert Liebmann [«Vorwärts» 1930 № 15, 17, № 198; 1931 № 9, 11,15, 23]; Frei nach dem Roman von Heinrich Mann "Professor Unrat" von Carl Zuckmayer und Karl Vollmöller [«Vorwärts» 1930 № 15, 17].

Стратегия оценивания реализуется лексемами с положительной коннотацией: отмечается факт перехода от немого кино к звуковому, дается высокая оценка актерам, исполнившим главные роли, а также режиссёрская работа:

1. der erste Ton- und Sprechfilm;

2. der große Erfolg;

3. der beste Sprech-und Tonfilm;

4. der vollkommenste Ton-und Sprechfilm;

5. ein Meisterfilm;

6. ein Fortschrittsfilm;

7. ein Kunstwerk;

8. eine Spitzenleistung;

9. ein Ton-Großfilm ${ }^{1}$

10. ein erstklassiger Film.

Необходимо отметить, что между стратегиями нет четких границ, наблюдается их взаимодействие. Фильм получил положительную оценку кинокритиков, следовательно, был рекомендован к просмотру.

Наиболее частотными существительными (в скобках указана частотность их употребления в рецензиях) являются GroßErfolg² (17), Erfolg (55), Tonfilm (56); последние два существительных в 25 рецензиях упоминаются 2 раза. Ereignis в большинстве случаев используется с семантикой «успешное событие». Лексема GroßErfolg написана вопреки правилам орфографии с целью привлечения внимания читателя, потенциального зрителя.

Среди других частей речи самыми частотными являются числительное erst (38), три прилагательных в превосходной степени: groß (33), gut (31), vollkommen (13).

1 Сохранена оригинальная орфография автора

2 Сохранена оригинальная орфография автора 
Проведенный анализ кинорецензий в газете «Deutsche Allgemeine Zeitung» не выявил стратегии информирования.

Стратегия оценивания реализуется с помощью атрибутивных словосочетаний с отрицательной коннотацией, при этом негативная оценка усиливается за счет отрицательной семантики как прилагательного, так и существительного (примеры 1,2,4,6):

1. eine bedauerliche Enttäuschung;

2. eine reine Enttäuschung;

3. die vollkommenste Enttäuschung;

4. ein miserabler Film;

5. ein umstrittener Film;

6. ein deutlicher Knacks;

7. ein minderwertiger Streifen;

8. misslungene Verfilmung.

Наиболее частотными существительными являются Untergang (44) и Enttäuschung (51). Кроме этого, в кинорецензиях зафиксированы следующие единицы этого семантического поля:

Knacks, Imitation, Parodie, Misserfolg, Veränderung des Romans, kaum Vollkommenheit, sentimentale Katastrophe.

Среди других частей речи самыми частотными являются причастие misslungen (18) и прилагательное miserabel (8).

Заслуживает внимания метафора Marlene sprengt jedes moralische Korsett (досл. Марлен разрывает любой моральный корсет), выражающая крайнюю степень негативной оценки и неприятия фильма.

\section{Выводы}

Дискурсивный подход к анализу кинорецензий на фильм «Голубой ангел» позволил установить несовме- стимость оценок ключевого коммуникативного события в киноискусстве 1930-1931 гг. Веймарской республики.

Выявленные вариативные языковые средства в кинорецензиях на фильм «Голубой ангел» в двух изданиях Веймарской республики находятся в отношении семантически взаимоисключающих средств (GroßErfolg Erfolg - Ereignis / Misserfolg - Untergang - Enttäuschung), что свидетельствует о социально обусловленном характере оценки кинофильма.

В рецензиях газеты социал-демократической партии Германии, ведущей партии левых сил того времени, отстаивающей интересы общества о социальной справедливости, дается высокая оценка фильму. Прагматическая цель авторов кинорецензий в издании - заинтересовать максимальное количество зрителей в просмотре этого социально заостренного фильма - определила выбор трех взаимообусловленных дискурсивных стратегий. Стратегия информирования поддерживает стратегию положительного оценивания, что находит свое выражение в выборе языковых средств (перечисление сведений о месте показа фильма, киностудии, о съёмочной группе, режиссере, актерах и др.).

Крайне негативная оценка фильма дана в рецензиях «Deustche Allgemeine Zeitung», отражавшей интересы консервативных социальных слоев общества, сторонников бывшей германской империи. Прагматическая цель рецензентов в этом издании - высказать жесткое критическое мнение о фильме и его создателях - предопределила выбор стратегии формирования отрицательной оценки, реализованной языковыми средствами с крайне отрицательной оценочной семантикой.

Результаты изучения дискурсивных практик немецкой кинокритики на фрагменте 1930-1931 гг. могут стать основой и предметом дальнейшего исследования всего исторического периода Веймарского кино.

\section{ЛИТЕРАТУРА}

1. Ванько Т.Р. Своеобразие языка кинорецензии // Вестник Московского государственного лингвистического университета. 2013. Вып. 26 (686). 3 емцова Л.А. Искусствоведческая рецензия как жанр массово-информационного дискурса: дис. ... канд. филол. наук. Волгоград, 2006.

2. Ильинова Е.Ю., Кочетова Л.А. Динамика репрезентации процессуальной составляющей спортивного события в диахроническом корпусе // Вестник ВолГУ. Серия 2, Языкознание. - 2017. - Т. 16, № 2. 47-57 с.

3. Иссерс 0.С. Коммуникативные стратегии и тактики русской речи. Эдиториал УРСС. М., 1999. 288 с.

4. Кочетова Л.А. Английский рекламный дискурс в динамическом аспекте: монография. — Волгоград: Волгоградское научное издательство, 2013.404 с.

5. Кочетова Л.А. Диахронный подход к изучению рекламного дискурса: теоретико-методологический аспект // Вестник Московского государственного лингвистического университета. Сер. Языкознание: Дискурс как социальная деятельность: приоритеты и перспективы. Ч. 1.- Москва: Рема, 2012. - Вып. 5 (638). $216-224 \mathrm{C}$.

6. Степанов Ю.С. Изменчивый образ языка науки XX века// Язык и наука 20 века- М.: РГГУ,1995. С. 10-35.

7. Троицкая Т.Б. Тактики реализации полемической стратегии в публицистическом дискурсе//Вестник Башкирского университета. Серия Филология и искусствоведение. 2008. Т3. № 3 с 530-534

8. Шкайдерова Т.В. Адаптация кинорецензии к новым медиаусловиям // Коммуникативные исследования. Омск, 2014. № 2. С. $141-145$. 
9. Эрман В.А. Кинорецензия как полидискурсивный и интердискурсивный текст (на материале немецких журналистских текстов): автореф. дис. ... канд. филол. наук. СПб., 2011.

(c) Новикова Алена Сергеевна (alenuchka.noff90@gmail.com).

Журнал «Современная наука: актуальные проблемы теории и практики»

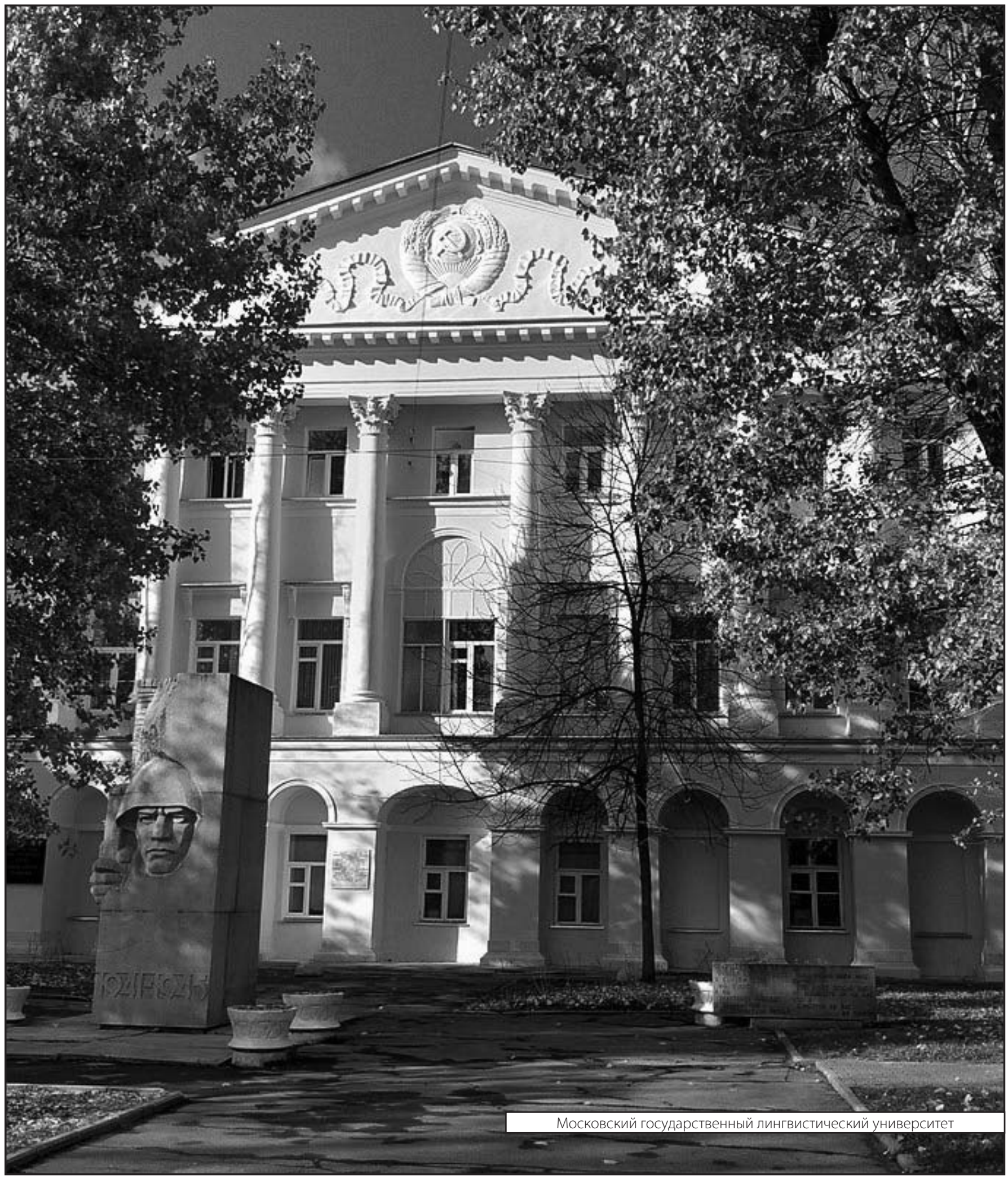

